\title{
EGFR NP_005219.2:p.H773_V774insNPH
}

National Cancer Institute

\section{Source}

National Cancer Institute. EGFR NP 005219.2:p.H773 V774insNPH. NCI Thesaurus. Code $C 98690$.

An insertion of the amino acid sequence asparag ine-proline-histidine between the histidine at position 773 and the valine at position 774 of the epidermal growth factor receptor protein. 